working paper

2019-15

Welfare Effects of a Non-Contributory Old Age Pension: Experimental Evidence for Ekiti State, Nigeria

Maria Laura Alzua Natalia Cantet Ana C. Dammert Damilola Olajide

June 2019

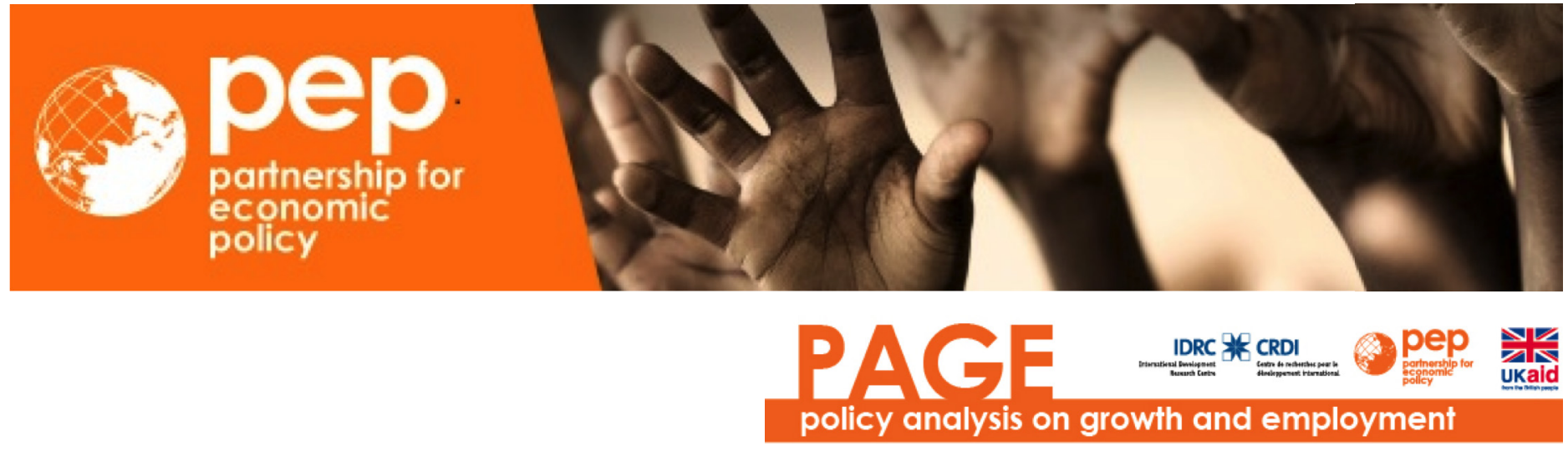




\title{
Welfare Effects of a Non-Contributory Old Age Pension: Experimental Evidence for Ekiti State, Nigeria
}

\begin{abstract}
Many countries in the developing world have implemented non-contributory old-age pensions. Evidence of the impact of such policies on the elderly in Sub-Saharan Africa is scarce, however. In this paper, we provide the first evidence from a randomized evaluation of an unconditional, non-contributory pension scheme targeted at the elderly in Ekiti State, Nigeria. Our findings show that treated beneficiaries self-reported better quality of life, more stable mental health, and better general health. We also provide evidence of spillover effects on labor outcomes and on household expenditure patterns as well as support for demandside interventions aimed at improving the welfare of elderly poor citizens and other household members.
\end{abstract}

Keywords: Randomized controlled trials; Aging; Non-contributory pensions; Health; Developing Countries.

JEL Classification: C21, C93, H31, H55, H75 138

Authors

Maria Laura Alzua

CEDLAS-Universidad Nacional de la Plata-

Conicet-PEP

Buenos Aires, Argentina

malzua@depeco.econo.unlp.edu.ar

Ana C. Dammert

Economics and International Affairs

Carleton University

Ottawa, Canada

anadammert@carleton.ca
Natalia Cantet

Department of Economics

University of Illinois at Urbana-Champaign, USA

cantet2@illinois.edu

\section{Damilola Olajide}

Initiative for Evidence Based

Development and Empowerment

Lagos, Nigeria

d.olajide@iebdem.org

\section{Acknowledgements}

This work was carried out with financial and scientific support from the Partnership for Economic Policy (PEP) with funding from the Department for International Development (DFID) of the United Kingdom (or UK Aid) and the Government of Canada through the International Development Research Centre (IDRC). The views and opinions expressed in this publication are those of the authors and do not necessarily reflect those of PEP. This RCT is registered at AEA RCT registry with code AEARCTR-0003147. 


\section{Table of contents}

$\begin{array}{ll}\text { I. Introduction } & \text { p.1 }\end{array}$

II. Background: Ekiti's Pension Program p.4

III. Research Design p.6

3.1. Randomization

3.2. Data Collection

3.3. Outcome Variables

3.4. Attrition

IV. Descriptive Statistics

4.1. Beneficiary Baseline Characteristics

V. Empirical strategy

5.1. Direct Effects of the Ekiti State Pension Program

5.2. Indirect Effects of the Ekiti State Pension Program

VI. Results: Direct Impact of the Program on the Beneficiaries

6.1. Mental Health

6.2. Vulnerability

6.3. Labor Market Outcomes

VII. Indirect Impact of the Program

7.1. Spillover Effects: Other Household Members

7.2. Household Income and Consumption

VIII. Discussion

References

p.20

Appendix 


\section{Introduction}

In recent decades, social-protection programs have expanded notably in developing countries (Baird, De Hoop \& Özler, 2013; Blattman, Fiala \& Martinez, 2013; and Handa et al., 2018). Many countries-especially in Latin America-have implemented conditional cash transfers to protect vulnerable children and, to a lesser extent, pensions to protect individuals against poverty in old age (Levy \& Schady, 2013). In most developed countries, old-age pensions are based on contributory systems (Walton \& Levy, 2009), which depend upon formal employment history. In the context of developing countries with large informal sectors, such contributory schemes tend to protect only a few individuals and exclude the most vulnerable (Dethier, Pestieau \& Ali, 2010). Indeed, only 20\% of beneficiaries eligible for pensions worldwide receive benefits (Pallares-Miralles, Romero \& Whitehouse, 2012). In Africa, this situation is significantly worse, and old-age protection averages less than $5 \%$ of the eligible population (World-Bank, 2012).

Rural Nigerians are mainly informal-sector workers in subsistence agriculture, which means that their access to formal-employment-related pensions or other types of retirement benefits is limited. In 2013, the regional government of Ekiti State implemented an unconditional, non-contributory pension program for citizens aged 65 and above. The target population were those who were receiving no assistance and whose income fell below the NGN 3,000 (\$19 USD) monthly threshold. Over a twelve-month period, the regional government provided eligible elderly in fifty-six randomly selected wards with an unconditional monthly cash transfer of NGN 5,000 (approximately $\$ 32$ USD), one-fourth of the average monthly cost of living in Nigeria (NGN 22,094).

We implemented a randomized experiment to test whether a non-contributory pension for old and vulnerable individuals would improve the welfare of the elderly in Nigeria. The randomization was conducted in Ekiti State at the ward level, the smallest administrative unit, to avoid contamination bias. Our sample consisted of 6,060 eligible elderly people and 23,517 household members across 112 wards.

We found that the program resulted in an improvement in self-reported mental health among beneficiaries in treated wards, as measured by the Geriatric Depression Scale, though 
the effects were smaller than those found by Bando, Galiani, and Gertler (2016) for Peru and Galiani, Gertler, and Bando (2016) for Mexico. Additionally, we found positive and statistically significant effects on self-reported satisfaction with life and a reduction in risky behaviors, as measured by the health index (Willmore, 2007). Moreover, treated individuals displayed significant reductions in vulnerability levels. Additional findings indicated a statistically significant increase in food security that was not complemented by fluctuations in financial inclusion level. Interestingly, neither labor-market participation (the decision to work or the number of hours worked) among elderly beneficiaries nor measures of community participation changed as a consequence of the pension program. We also did not find effects on the decision to work of other household members. The program did, however, have a statistically significant impact on the intensive margin of household members because per capita hours of work decreased by approximately one hour per week.

We also tested whether the size and the spending patterns of households were affected by the program. Compared to control households, treated households were significantly smaller and had greater per capita income and savings. They also spent less in general and on healthcare. Unfortunately, we did not have information about why household members left households, so we can only speculate. A reduction in household size could be consistent with a better bargaining position of the elderly as a consequence of their improved financial position. Also, younger members might have been free to leave the household once they no longer had to participate in the support of their elderly relatives. The observed increase in income and savings also seemed consistent with the increase in income resulting from the transfer. The sign on the health expenditures is ambiguous. It could be the case that increases, because the demand for healthcare increases with income, so the effect of the transfer could have a positive effect. Also, it could be the case that health spending is focused on children. This was plausible in our context because the elderly had less access to healthcare in their rural context. If younger people were to leave the household, health expenditures could be expected to decrease.

Our results are in line with recent literature on mental health in developing countries. Mental and physical health have been positively associated with unconditional cash transfers. Haushofer and Shapiro (2016) analyzed the effects of a randomized unconditional cash 
transfer household program in Kenya and found increases in overall levels of psychological well-being. They also found a large impact on productive outcomes-livestock, durable assets, and agriculture-and on business revenue nine months after payments began. Additionally, Bando et al. (2016) and Galiani et al. (2016) showed that old-age pensions decreased geriatric depression and the number of paid work hours significantly in Mexico and Peru, respectively. These papers found that improved mental health was linked to labormarket outcomes because unemployment led to greater depression (Galiani, Gertler \& Bando, 2016). In the same vein, other studies have found that improved mental health permitted the allocation of time to leisure activities (Pfutze \& Rodríguez-Castelán, 2015; Krueger \& Mueller, 2012; Knabe et al., 2010).

Pension schemes, however, may also have unintended negative consequences. Joubert (2014) found that a state-provided non-contributory pension scheme in Chile led to a reduction in labor-force participation among older individuals as well as a transfer of workers from the formal to the informal labor market. Duflo (2003) and Carvalho de Filho (2008) showed that, although pension beneficiaries spent more on basic needs like food and medicines, they also increased cigarette smoking.

In the economics literature, various writers have examined the effects of cash transfers on the welfare of household members living with beneficiaries and, importantly, have suggested that beneficiaries' gender plays a role. Duflo (2000) analyzed the spillovers of a pension-reform program in South Africa that raised pensions for the black population and found that pensions had a positive impact on the height-for-age of girls born after the reform. Overall positive associations have, moreover, been reported for such outcomes as child enrollment (Duflo, 2003), household composition, and private transfers.

Our work is, to the best of our knowledge, the first randomized experiment implemented in Nigeria to test the effect of a unconditional cash transfer on the elderly and is directly related to a more recent strand of literature that links increases in income to improved happiness and reduction in stress. Haushofer and Shapiro (2016) and Haushofer and Fehr (2014), have written specifically about the importance of mental health considerations in the design of poverty-alleviation programs. The Nigerian context provides additional insight because we included rural, poorer, and more vulnerable households. 
A key challenge in public finance in developing countries is the question of how fiscal policy (such as cash transfers) can be used to address issues elder poverty and the vulnerability of the elderly to shocks. A major aspect of this challenge is an assessment of the effectiveness of public-finance options in an environment of increasingly constrained budgets. The fact that the Ekiti program was implemented by a local African government points to potential expansion to other developing countries with vulnerable elderly populations.

There are, however, several challenges to implementing rigorous impact evaluations in Sub-Saharan countries in which violence and fiscal policy constraints, among other factors, limit data collection. In fact, we encountered several problems with data collection, which was conducted by the statistical office of Ekiti State. Several baseline modules and follow-ups could not be administered because of budgetary constraints. A food diary to track food consumption could not be provided, for example, which made it impossible to estimate potential impacts on food consumption. Additionally, labor spillovers could not be identified in the second follow-up because we were not able to survey all household members. These points are important because household consumption and employment (Haushofer \& Shapiro, 2016 and Angelucci \& De Giorgi, 2009) are direct mechanisms through which schemes affected beneficiaries. Our randomization, however, allowed us to make causal inferences regarding several important economic, social, and psychological outcomes.

\section{Background: Ekiti's Pension Program}

Since the end of the Nigerian civil war (1967-1970), the elderly (defined as those aged 65 and over) increased from $2.8 \%$ of the population in 1970 to $3.2 \%$ in 2011 . This demographic transformation has largely been the result of declining fertility and increasing longevity. 1 In this context, the aging population represents a challenge for Nigeria's ability

\footnotetext{
1 The fertility rate dropped from $6.1 \%$ in 1990 to $5.2 \%$ in 2014 while the birth rate fell from $6 \%$ to $3.8 \%$ in the same period. Life expectancy also increased from 46.7 years in 2005 to 52.6 years population represents a key
} 
to provide decent living conditions and improve the well-being of the elderly.

Over half of the Nigerian population lives in rural areas, and most of these individuals are over 65. Rural-urban migration in Nigeria has been increasing at a rate of 3.5\% per year, one of the highest rates in Africa. The major problem is that most of elderly population has worked in the informal sector all their productive lives, mainly in subsistence agriculture and, therefore, has no access to formal employment-related pensions or other retirement benefits. Moreover, alternative means of support in old age are limited because most elderly people do not have savings and are vulnerable to social and economic shocks.

The social-policy response of the Nigerian government to issues affecting the elderly has been weak. Some limited legislation has been passed to protect formal-sector workers, but it does not extend to informal-sector activities.2 Given social norms and the level of informality in Nigeria, most of the elderly population has limited safety nets. For most individuals, their children or close relatives remain the most reliable source of support in old age (National Population Commission, 2011).3 The fact that many individuals of working age leave their homes means that an increasing number of elders have no completely reliable support system.

This paper focuses on a program implemented in 2011 by the regional government of Ekiti, a small, rural state located in southwest Nigeria. Ekiti comprises sixteen Local Government Areas (LGA) and 163 electoral wards.4 Its population is estimated at 2.4 million, and most inhabitants are either public-service workers or are involved in informal-sector activities such as subsistence agriculture and market trading. The elderly, defined as individuals 65 or older, account for $3.6 \%$ of the population, with a dependency ratio of $6.1 \%$ in 2006 based on the national census (National Population Commission, 2011).

Motivated by the government's concern for the well-being of the elderly in the state, the government of Ekiti decided to implement an unconditional and non-contributory cash

\footnotetext{
challenge for Nigeria in its capacity to provide decent living conditions and improve the well-being of the elderly.

${ }^{2}$ The National Policy on the Care and Wellbeing of the Elderly in Nigeria, for example, was finalized in 2003 but successive administrations have failed to implement it (Olajide et al. 2013; Holmes and Morgan 2012)

${ }^{3}$ Seventy percent of the elderly reside with children or relatives, and only $10 \%$ live alone.

4 Each LGA is administered by a Local Government Council and is subdivided into wards. A typical LGA has between ten and sixteen wards. At the time of our study, Ekiti was comprised of sixteen electoral wards.
} 
transfer program. The government's concern was that the majority of elderly citizens were unable to engage in rigorous economic activities, thereby leaving them vulnerable to social and economic shocks and old-age poverty. Individuals in treated wards were informed of the program during the month of October 2013, and payment of cash benefits began in November 2013. Payments were made at designated centers monitored by the officials of the implementation agency.

The intervention was conducted for twelve months between November 2013 and October 2014. Eligible beneficiaries (citizens aged 65 years who were not receiving pensions and whose monthly income was less than NGN 3,000 (\$19 USD)) received a monthly cash payment of NGN 5,000 (approximately $\$ 32$ USD). The payment represented around 28\% of the national minimum wage of NGN 18,000 at the time and $23 \%$ of the average monthly cost of living in Nigeria (NGN 22,094). This comes out to around one dollar per day, which is in line with the international poverty line.

\section{Research Design}

\subsection{Randomization}

In order to capture the effects of the policy intervention on the elderly, we designed a cluster-randomized controlled trial at the ward level. Data were collected at three stages: (i) at baseline, (ii) at first follow-up, six months following the baseline survey; and (iii) at second follow-up, six months following the first follow-up survey.

The program required potential beneficiaries to be 65 years-old or above, to be receiving no pension, and to have a monthly income of less than NGN 3,000 (\$19 USD). To identify the effects of the program, we oversampled all wards with at least sixty elderly citizens. Based on administrative information, 112 wards were identified with the required number of beneficiaries. Power calculations were conducted using several variables from the baseline survey: total household income, per capita income, and per capita health 
expenditure. An intracluster correlation of 0.10 led us to a sample 112 selected wards, 56 of which were assigned to the treatment group and the other half to the control. Importantly, the population is highly homogeneous within a ward so, to avoid contamination, every individual in the ward was assigned to the treatment or control group.

The random allocation of electoral wards was carried out after the baseline survey conducted between July and September 2013. The total sample consisted of 6,326 eligible individuals. The treatment group included 3,230 individuals (51.1\% of the total), and 3,096 individuals were placed in the control group.5

Table 1 shows the results of the randomized assignment and the distribution of the eligible beneficiaries into treatment and control wards. As the table shows, the distribution of eligible beneficiaries was fairly balanced between treatment and control wards.

\subsection{Data Collection}

The data for our analysis came from three surveys carried out by the research team in partnership with the Government of Ekiti State. The baseline survey, conducted between JulySeptember 2013, collected information on eligible beneficiaries and on some members of their households before the disbursement of cash transfers and before random assignment to treatment/control groups.

The first follow-up survey was conducted between June-September 2014, after the program had been in operation for almost six months. As in the baseline survey, this round included a household module and an individual interview with the older adult. Finally, after a minimum of six months had elapsed since the first follow-up, a second follow-up survey was administered between April-July 2015.6

All the surveys collected detailed information from the beneficiary concerning household demographics, household members' labor activities and outcomes, and

5 An additional 23,517 household members of eligible beneficiaries were also interviewed at baseline. 6 Our original intention was to interview the beneficiaries along with other members of their households. For reasons beyond our control, however, we were only able to reliably survey the beneficiaries. 
household consumption. The questionnaires contained five modules: (i) the General Beneficiary information module, which collected information on the respondent's identity and relationship with the beneficiary, among other things; (ii) the Household Member module, which collected information on household members of eligible beneficiaries; (iii) the General Household module, which collected information on the household characteristics of the beneficiary; heads of household, defined as the person (beneficiary or otherwise) who provided the required information, were also interviewed; (iv) the Beneficiary module in which elderly persons were interviewed individually, including widows/widowers; and $(v)$ the Program Implementation module, during which individuals in treatment areas were interviewed in order to collect specific information regarding program implementation (e.g. how benefits were collected).

\subsection{Outcome Variables}

Specific mental health questions were added to the questionnaires for both follow-up surveys. In particular, we considered depressive symptoms and lack of self-esteem as indicators of mental health and used the Geriatric Depression Scale developed by Sheikh and Yesavage (1986). Responses were summed to give individual scores. A higher score indicated a greater probability that the individual's mental health was poor.

A similar approach was taken to measure other mental health outcomes such as life satisfaction and health risks. The former was constructed using nine variables intended to asses happiness and satisfaction. Health risk considered how much the beneficiary drank or smoked in previous months. Additional information regarding how each variable was constructed is presented in Appendix A.1.

We also analyzed the general vulnerability of the beneficiary's household, defined as the ability of a household member to cope with social, economic, or environmental shocks when they occurred. The first and second follow-up surveys contained twenty-four questions used to construct three composite variables. The first was a PCA index of several risk and vulnerability measures (such as child labor, crime, migration, and health). A second variable 
indicated food security, and a third described level of financial inclusion through questions about the use of the banking system.

The impact of the program on the beneficiary labor supply indicator was calculated using elderly subjects' responses to questions regarding whether and how many hours they had worked during the previous six months. These variables were also measured for other household members at the first follow up (see Appendix B.2 for the indirect effects of the program). An additional variable, named Community Participation, was designed to measure whether beneficiaries felt integrated into their own communities. Appendix A.1 contains a complete list of questions and further details.

The last set of outcomes were estimated at the household level. Specifically, we studied the effect of the program on household size and the Hyperbolic Sine of expenditure and income variables.7 A more detailed description of what these variables contain is provided in Appendix A.2.

\subsection{Attrition}

As a consequence of the nature of the intervention, where it took place, and the fact that the beneficiaries were 65 or older, attrition was an important consideration. Attrition can result from relocation, migration to other cities, death, or other factors.

Table 1 provides details of attrition in the two follow-ups. Unfortunately, the data do not allow us to establish the specific nature of attrition. Attrition was low in the treatment group (1\% of treated individuals) and higher in the control group (approximately 9\%). These attrition levels suggest that our results may be the upper bound for the effects of the pension program on the elderly population of Ekiti State.

Appendix Table B1 provides a detailed description of the variable balance with attrition. As can be noted, the distribution of the eligible beneficiaries remained balanced

7 The Hyperbolic Sine transformation is defined as $\log (y+(y 2+1) 1)$, which means that estimation is defined for individuals with zero expenditure or income. 
between the treatment and control wards even after attrition was accounted for. While the differences in individual characteristics between treatment and control wards were small and not significant, levels were also close to the baseline presented in Table 1.

\section{Descriptive Statistics}

\subsection{Beneficiary Baseline Characteristics}

Table 2 reports summary statistics for the elderly population in our sample. This table shows the means and the standard deviations across treatment and control groups. We also present the p-value of a joint test of equality of means across groups. As expected from randomization, both groups were balanced in terms of age, gender, marital status, literacy, labor status, network support, and health.

The beneficiaries in the treatment and control group were 78 years old on average; only about $30 \%$ of the sampled individuals were male. Neither difference was significant. Most individuals in both groups were widows/widowers: $42.8 \%$ of treated individuals and $46 \%$ of the control group report reported this status. They were followed by individuals who reported being in a monogamous relationship $37.9 \%$ in the treatment group and $39.3 \%$ in control group) or in a polygamous relationship (13.5\% and $10.8 \%$, respectively). There were no statistically significant differences in any of these variables.

The average number of people living with the beneficiary was 3.030 among treated households and 2.91 among the control group. Additionally, persons in the treated wards were slightly more likely than their counterparts in control localities to be literate $(11.7 \%$ vs. $9.7 \%)$ and to have attended school (16.4\% vs. $12 \%$, respectively). This last difference is significant at the $10 \%$ level.

Panel B is a list of variables that describe beneficiaries' labor characteristics. The percentage of the elderly population that worked was $26.3 \%$ in treated wards and $24.2 \%$ in the control wards. Most employed beneficiaries worked in subsistence farming $(19.8 \%$ in the 
treatment wards and $18.9 \%$ in the control wards). In Table 2, we report that an additional $5.2 \%$ in the treatment wards and $3.9 \%$ worked in non-farming jobs, including as salespeople or artisans. Non-subsistence farming was insignificant among the individuals in our sample. None of these differences was statistically significant.

The panel in Table 2 displays the support given to the elderly population in the treated wards. The share of treated individuals receiving monetary support from someone in their social network was $41.8 \%$, which was similar to the control group (45.5\%). Ten percent of treated beneficiaries and $13 \%$ of non-treated individuals received support from a child, and approximately half of this group reported help from other relatives. The amount of support given to beneficiaries was NGN 1,001 on average among the elderly who lived in treated wards and NGN 1,082 among those who did not.

Finally, only a small share of the studied individuals across treatment and control groups reported smoking or drinking alcohol (approximately $4.9 \%$ and $11.1 \%$ vs. $6.65 \%$ and $10.9 \%$, respectively). We also presented three self-assessment measures: an overall health level assessment, a measure of confidence in their abilities, and another that indicated to what extent subjects felt integrated into their communities. The self-reported health assessment score averaged 2.7 points out of a possible five for both groups. The average confidence-in-their-own abilities score was 2.6 , and the self-reported inclusion score was 2.3 points for both groups.

\section{Empirical strategy}

\subsection{Direct Effects of the Ekiti State Pension Program}

We began our analysis by estimating the intent-to-treat (ITT) effects of the Ekiti State pension program on beneficiaries. To do so, we estimated the following empirical model, both six months and twelve months after beneficiaries started receiving payments: 
$K$

yijt $=\alpha+\beta 1$ Treated wardj + ) $\beta k X k i+\theta k+i j t_{-}$

$k=2$

where i denotes an individual, j denotes a ward, and $t=1,2$ refers to either the first or second follow-up periods. Additionally, the variable yijt denotes a particular outcome that affects the beneficiary directly. For example, yij might be the self-reported geriatric depression level of individual $\mathrm{i}$ who lives in the ward $\mathrm{j}$ at the time $\mathrm{t}$.

We analyzed outcome variables that described the overall well-being of the elderly population in our study. We classified them into three categories: mental health, vulnerability, and labor supply. Mental health variables included scores on the Geriatric Depression Scale (created by Sheikh and Yesavage, 1986), which ranged from 0 to 15; a life satisfaction index constructed on the same model, and a composite measure of beneficiaries' risky behaviors during the month prior to the interview. Next, the vulnerability set was created from a PCA index of the general vulnerability level of the beneficiary, an index of food shortage, and a measure of the degree to which beneficiaries participated in the financial system. Finally, labor-supply variables included whether the person was working or not, the number of hours worked, and a community-participation index. More details regarding how these variables were created is provided in Appendix A.

Treated wardj is an indicator variable of whether the ward in which individual i lived was eligible to receive the unconditional cash transfer. The coefficient on Treated wardj, $\beta 1$, is the main coefficient of interest that captured the average difference in means between the treatment group (people who lived in randomly selected treated wards) and the control group (those who did not reside in randomly selected wards). This coefficient can be interpreted as the impact of receiving an Ekiti State cash transfer.

We defined $\mathrm{Xki}$ as the set of individual level covariates that had to be controlled so that $\beta 1$ would be an unbiased estimate of the relationship between receiving the pension and the outcome of interest. Throughout our analysis, Xki included an indicator variable that took the value of one if the beneficiary was male, another for literacy level, and another for the age of individual i. Finally, we denoted $\theta k$ as the local government fixed effects.

All the ITT estimates were calculated by adjusting the standard errors for clustering at the ward level. ijt was the error term. 


\subsection{Indirect Effects of the Ekiti State Pension Program}

Equation 2 describes the indirect effects of the intervention at the household level for the first follow-up survey:

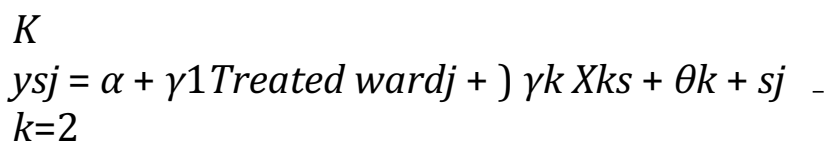

Where $s$ was the household identifier and $\mathrm{j}$ was the ward. Following a similar notation to the previous equation, ysj denoted the outcome of interest at this level (such as household income level) and Treated wardj was an indicator variable of whether the household was located in a treated ward. Xki were household covariates and $\theta \mathrm{k}$ represented local government fixed effects. Standard errors were clustered at the ward level, and the coefficients were corrected for multiple-hypothesis testing using the Hochberg correction. For each household member other than the beneficiary, we studied the number of hours worked and the entire number of hours worked by the whole household. Appendix A contains a detailed description of how these variables were constructed.

Finally, Equation 3 measured the effects of the program on the labor-market outcomes of household members who were not the direct beneficiaries of the program:

$K$

$y i j=\alpha+\delta 1$ Treated wardj + ) $\delta k X k i+\theta k+i j \quad$ $k=2$

Again, yijt denoted the labor outcome of those who reported living in the same household as a beneficiary. Additionally, $\delta 1$ was the coefficient of interest that captured the difference in means of labor-market outcomes between the relatives of treated and nontreated beneficiaries (noted as Treated wardj ). As described in the Outcome section, these variables included a proxy of household and the inverse hyperbolic sine transformation of the income, spending, and savings of the household.

Finally, in this equation, Xki were a set of individual level covariates for the members of household who did not receive payments and $\delta k$ were local government fixed effects. Standard errors were clustered at the ward level. 


\section{Results: Direct Impact of the Program on the Beneficiaries}

In this section, we present our main findings from the ITT direct and indirect effects of the program (Equations 1 through 3). Because we were testing a large number of outcomes, we corrected all estimation coefficients for the issue of multiple inference using index variables and family-wise error rate correction (FWER).

\subsection{Mental Health}

Columns (1) and (2) of Table 3, report the program's significant positive effects on the mental health of the beneficiaries. Depression (as measured by GDS score) decreased in the treatment group with respect to the control groups: Overall scores decreased by 0.283 (SE 0.135 ; significant at the $5 \%$ level) among beneficiaries at the six-month benchmark. The effect on the GDS, however, did not significantly persist twelve months following implementation. Similarly, treated individuals engaged in less risky activities than the untreated group in the period under examination (health-behavior scores significantly decreased by 0.097 (SE 0.045) and 0.068 (SE 0.046) for the six- and twelve-month periods).

Table 3 also shows a significant effect of the program on beneficiaries' Life Satisfaction level for both periods in Columns 3 and 4. Six-months after the program began, the average difference in the index was 0.491 (SE 0.188) than the individuals that did not receive the treatment. The coefficient for the twelve month regression increased to 1.024 (SE 0.290). Both estimates survived FWER correction and were significant at the $5 \%$ level.

The results remain unchanged when individual level controls and local government fixed effects were added, as shown by Appendix Table B.2. The effects maintained the same level of significance, and the coefficients were similar in magnitude. 


\subsection{Vulnerability}

As Table 4 shows, the program appears to have had a significant effect on the vulnerability index. At the six-month interval, the index shrank by 0.160 points (SE 0.094 , significant at the $10 \%$ level) and, by the twelve-month threshold, it decreased by 0.333 points (SE 0.119, significant at the $1 \%$ level). In addition, the food security index decreased 0.226 points (SE 0.128) and 0.404 points (SE 0.124), respectively.

In order to further understand vulnerability in the context of Nigeria, we analyzed whether the cash transfer program changed beneficiaries' decisions to use formal financial institutions. The evidence in Table 4 suggests that cash transfers had no effect on the banking behavior of beneficiaries as neither coefficient is significant for the two periods.

The results persisted even when individual-level controls and local government fixed effects were added. The estimated regression coefficients are presented in the Appendix Table B.3.

\subsection{Labor Market Outcomes}

Our evidence showed that beneficiaries' labor-market participation did not significantly change during the period under examination. Estimation results for our main labor variables are shown in Table 5. Columns 1 and 2 report the difference in the outcomes between control and treatment beneficiaries' labor participation, i.e. the extensive margin. These estimates are extremely small and mostly insignificant, suggesting that the program did not affect the decisions regarding whether or not to work.

Furthermore, the intensive market was not affected by cash transfers in the short run because estimates were small and insignificant. For the twelve-month follow-up, however, the estimate more than tripled and became significant. In the second follow-up, the coefficient became 1.493 hours (SE 0.695, significant at the $1 \%$ level), indicating that beneficiaries worked an hour and a half less on average than individuals in the control group. It should be noted that the control group means were generally low such that few individuals 
in our sample reported holding full-time positions.

Finally, community participation, shown in Columns 5 and 6, did not significantly change as a consequence of cash transfers during the year under analysis, and size is negligible. Nevertheless, the control group mean was low and standard errors were high. More statistical power might be required to capture changes in this index.

Appendix Table B.4 presents the estimated regression coefficients for the same regressions with individual level controls and LGA fixed effects. As shown in this table, coefficients were consistent with those in the main specification.

\section{Indirect Impact of the Program}

\subsection{Spillover Effects: Other Household Members}

The estimated impact of the program on the labor outcomes of non-beneficiaries is shown in Table 6. It should be noted that these estimates were available only for the sixmonth survey, so they reflect only short-run spillover effects of cash transfers on beneficiaries' households. As Table 6 shows, the program did not have an impact on the likelihood that a household member would work (Columns 1 and 2).

In contrast, the next pair of columns show that the total number of hours worked decreased by 6.4 hours (SE 2.879), and the per capita level significantly decreased by approximately one hour per week (1.074 hours, SE 0.342). Thus, the Ekiti state cash transfer affected the intensive margin rather than the extensive one.

Consistent with the individual level, the weekly hours worked per household decreased by approximately 6.5 hours across the entire household. Given that the average total number of hours worked by a household is 52 hours, the treatment effects represents eleven percentage points. 


\subsection{Household Income and Consumption}

In Table 7, we present total household level income, spending, and savings to consider the financial impact of the program. Because of the large number of variables, we also corrected all estimation coefficients for the issue of multiple inference using FWER pvalues. In the first place, the size of households with treated individuals was significantly lower (by 0.454 members; SE 0.067 , significant at the $1 \%$ level) than was household size among the control group.

Columns 2 through 6 show the inverse hyperbolic sine of total monthly income, spending, and savings for households. As Column 2 shows, Ekiti program beneficiaries had higher incomes than did the control group (0.069 percentage points; SE 0.028). Additionally, the coefficients for total and healthcare spending (Columns 3 and 4 ) were negative and statistically significant. They amount to -0.064 percentage points (SE 0.020, significant at the $1 \%$ level) and -0.298 percentage points (SE 0.109, significant at the $5 \%$ level). Finally, savings in households in which a cash-transfer recipient resided was 2.135 (SE 0.396) higher and was significant at the $1 \%$ level.

\section{Discussion}

This study was motivated by the fact that developing countries, especially those in Africa, have large informal sectors. At the same time, traditional support systems based on family and kinship networks in Sub-Saharan Africa are very strong, and household and family members are still considered the main sources of support for the elderly. Thus, younger household members may find it costlier to accumulate human capital if they have to allocate both pecuniary and non-pecuniary resources to the assistance of the elderly family member.

An important public-financing challenge in developing countries relates to how fiscal policies such as cash transfers can address elder poverty and the vulnerability of the elderly to shocks. Recent decades have seen expansions of social-protection programs in developing 
countries aimed at improving the well-being of vulnerable populations. Most such programs cater to the youngest population, and protections have been more limited for the elderly not covered by social security. More recently, some governments in developing countries have started schemes such as a non-contributory pensions targeted at elderly citizens who have no access to formal retirement pensions. It is believed that this provides a way to improve the well-being of the elderly as well as alleviate old-age poverty in a context in which the aging population is growing rapidly all over the world. This increase is largely the result of improved living conditions, higher incomes, and demographic changes.

As in other countries in Sub Saharan Africa, the aging population is a significant challenge for Nigeria's capacity to provide decent living conditions and improve the wellbeing of the elderly. Over half of Nigerians live in the rural areas, and a considerable proportion of these are elderly. Most of the elderly population has worked in the informal sector all their productive lives, mainly in subsistence agriculture, and therefore have no access to formal employment-related pensions or other retirement benefits.

We conducted a randomized experiment to test the introduction of an unconditional, non-contributory pension targeted at the elderly in Ekiti State in Nigeria. Our findings showed improvements in beneficiaries' mental health, quality of life, and health. Additionally, other household members reduced total hours worked, and household income dropped, which means that spending patterns changed as a result of the cash-transfer program. Savings increased and overall spending and healthcare expenses were reduced. Intriguingly, we also found a reduction in number of household members.

Overall, our results suggest that the Ekiti State pension program had a positive effect on the lives of the individuals who received the cash transfer. As we have acknowledged, our data do not allow us to provide evidence of long term spillovers. However, the increase in the quality of life, the decrease in the vulnerability, and the reduction in household size are consistent with a change in the bargaining position of the elderly who were in an improved financial position as a consequence of the cash transfer. Alternatively, we hypothesized that cash transfers diminished younger members' cost of caring for the elderly, making it easier for them to leave the household while improving the conditions of those who stayed behind.

We have demonstrated that demand-side interventions benefit not only the elderly 
who receive those benefits but also their immediate families and other household members. Our findings are in line with the growing recognition of the role of the older generation in the household as agents of change and development. Social protections for the elderly may produce greater spillovers in their networks by loosening budget constraints and allowing beneficiaries' family members the freedom to work less.

The Ekiti State intervention was the first of its kind to be implemented at the regional level in Nigeria and in West Africa, where properly assessing the effectiveness of publicfinance options in the context of increasingly constrained budgets presents a special challenge. As our results suggest, a small but reliable and regular transfer income can help address the intergenerational transfer of poverty by improving the elderly population's overall mental health and changing the ways in which households allocate resources. 


\section{References}

Angelucci, M. and De Giorgi, G. (2009). Indirect effects of an aid program: How do cash transfers affect ineligibles' consumption? American Economic Review, 99(1), 486-508.

Baird, S., De Hoop, J., and Özler, B. (2013). Income shocks and adolescent mental health. Journal of Human Resources, 48(2), 370-403.

Bando, R., Galiani, S., and Gertler, P. (2016). The Effects of Non-Contributory Pensions on Material and Subjective Well Being. Technical Report, National Bureau Of Economic Research.

Blattman, C., Fiala, N., and Martinez, S. (2013). Generating skilled self-employment in developing countries: Experimental evidence from Uganda. The Quarterly Journal of Economics, 129(2), 697-752.

Carvalho de Filho, I. E. (2008). Old-age benefits and retirement decisions of rural elderly in Brazil. Journal of Development Economics, 86(1), 129-146.

Dethier, J.-J., Pestieau, P., and Ali, R. (2010). Universal minimum old age pensions: Impact on poverty and fiscal cost in 18 Latin American countries. The World Bank.

Duflo, E. (2000). Child health and household resources in South Africa: Evidence from the old age pension program. American Economic Review, 90(2), 393-398.

Duflo, E. (2003). Grandmothers and granddaughters: Old-age pensions and intra-household allocation in South Africa. The World Bank Economic Review, 17(1), 1-25.

Galiani, S., Gertler, P., and Bando, R. (2016). Non-contributory pensions. Labour Economics, 38, 47-58.

Handa, S., Natali, L., Seidenfeld, D., Tembo, G., Davis, B., Team, Z. C. T. E. S., et al. (2018). Can unconditional cash transfers raise long-term living standards? Evidence from Zambia. Journal of Development Economics, 133, 42-65.

Haushofer, J. and Fehr, E. (2014). On the psychology of poverty. Science, 344(6186), 862867.

Haushofer, J. and Shapiro, J. (2016). The short-term impact of unconditional cash transfers to the poor: Experimental evidence from Kenya. The Quarterly Journal of Economics, 131(4), 1973-2042.

Holmes, R. and Morgan, J. (2012). Social protection in Nigeria: Mapping programmes and their effectiveness.

Joubert, C. (2014). Pension design with a large informal labor market: Evidence from Chile.

Knabe, A., Rätzel, S., Schöb, R., and Weimann, J. (2010). Dissatisfied with Life but Having a Good Day: Time-Use and Well-Being of the Unemployed. The Economic Journal, 120(547), 867-889.

Krueger, A. B. and Mueller, A. I. (2012). The lot of the unemployed: A time use perspective. Journal of the European Economic Association, 10(4), 765-794. 
Levy, S. and Schady, N. (2013). Latin America's Social Policy Challenge: Education, Social Insurance, Redistribution. Journal of Economic Perspectives, 27(2), 193-218.

National Population Commission (2011). Population distribution by Age and Sex: 2006. Census Priority Tables, Vol. 4.

Olajide, D., Ezeibe, A., Sotola, O., Gold, K., Olufemi, O., and Adebayo, F. (2013). Randomised evaluation of unconditional cash transfer scheme for the elderly in Ekiti State, Nigeria.

Pallares-Miralles, M., Romero, C., and Whitehouse, E. (2012). International patterns of pension provision II: A worldwide overview of facts and figures.

Pfutze, Tobias and Rodríguez-Castelán, Carlos (2015). Can a Small Social Pension Promote Labor Force Participation? Evidence from the Colombia Mayor Program.

Washington, DC: World Bank Group. http://documents.worldbank.org/curated/en/577061468197093248/Can-a-smallsocial-pension-promote-labor-force-participation-evidence-from-the-ColombiaMayor-program.

Sheikh, J. I. and Yesavage, J. A. (1986). Geriatric depression scale (GDS): Recent evidence and development of a shorter version. Clinical Gerontologist: The Journal of Aging and Mental Health.

Walton, M. and Levy, S. (2009). No Growth without Equity? Inequality, Interests, and Competition in Mexico. The World Bank.

Willmore, L. (2007). Universal Pensions for Developing Countries. World Development, 35(1), 24-51.

World-Bank (2012). World Development Report 2013: Jobs, 435-444. Taylor \& Francis. 


\section{Appendix}

Table 1: Attrition

$\begin{array}{llll} & \text { Baseline } & \text { Follow-ups } & \text { Attrition Percent } \\ \text { Treatment } & 3,110 & 3,071 & 1.254 \% \\ \text { Control } & 3,286 & 2,988 & 8.764 \% \\ \text { Total } & 6,396 & 6,059 & 5.268 \%\end{array}$

Table 2: Descriptive Characteristics, Full Sample

Treatment Control

Diff. P-value

0.331

0.674

0.444

0.671

0.131

0.308

0.209

0.083

0.582

0.790

0.282

0.276

Mean SD Mean SD

Panel A: Demographics

$\begin{array}{lllll}\text { Age } & 78.149 & 12.701 & 78.467 & 12.658 \\ \text { Male } & 0.306 & 0.856 & 0.315 & 0.849 \\ \text { Household size } & 3.030 & 6.258 & 2.910 & 6.192 \\ \text { Monogamous status } & 0.379 & 1.353 & 0.393 & 1.340 \\ \text { Polygamous status } & 0.135 & 0.715 & 0.108 & 0.709 \\ \text { Widowed } & 0.428 & 1.378 & 0.463 & 1.366 \\ \text { Literacy } & 0.117 & 0.628 & 0.097 & 0.623 \\ \text { Attended School } & 0.164 & 1.004 & 0.120 & 0.995\end{array}$

Panel B: Labor

Employed

$0.263 \quad 1.540$

$0.242 \quad 1.524$

Subsistence farmer

$0.198 \quad 1.363$

$0.189 \quad 1.350$ 


$\begin{array}{lllll}\text { Non subsistence farmer } & 0.008 & 0.160 & 0.012 & 0.159 \\ \text { Other-non farming job } & 0.052 & 0.482 & 0.039 & 0.478\end{array}$

Panel C: Social Network Support

$\begin{array}{llllll}\text { Receives Support } & 0.418 & 1.357 & 0.455 & 1.345 & 0.274 \\ \text { Support Child } & 0.103 & 0.951 & 0.139 & 0.942 & 0.131 \\ \text { Support Relative } & 0.067 & 1.034 & 0.097 & 1.024 & 0.239 \\ \text { Amount in NGN } & 1001.48 & 3679.80 & 1082.67 & 3647.41 & 0.38\end{array}$

Panel D: Health Behavior

$\begin{array}{llllll}\text { Smokes } & 0.049 & 0.672 & 0.026 & 0.665 & 0.167 \\ \text { Alcohol consumption } & 0.111 & 1.025 & 0.109 & 1.014 & 0.939 \\ \text { Health Self-Assessment } & 2.769 & 3.515 & 2.686 & 3.478 & 0.348 \\ \text { Confidence in own ability } & 2.570 & 6.101 & 2.562 & 6.028 & 0.960 \\ \text { Inclusion level } & 2.338 & 4.530 & 2.203 & 4.467 & 0.242\end{array}$

$\mathrm{N}$

$\begin{array}{llll}\text { Joint F-test } & 3286 & 3110 & 0.227\end{array}$

Notes: Household size indicates the number of people living in the same household as the beneficiary. "Literacy" and "attended school" are self-explanatory. All variables in panels B, $C$, and D are reported for the month prior to the interview. "Hours Worked" is reported as the average number of hours worked per day during the previous month. Amount is the number of NGN received in a month by the beneficiary. All variables in Panel D were self-reported. Health self-assessment scores ranged from 0 to 5.

***Significant at the $1 \%$ level.

**Significant at the $5 \%$ level.

*Significant at the 10\% level. 19 
Table 3: Direct Outcomes: ITT Effects of the Ekiti State Pension Program (Mental Health)

\section{Geriatric Depression Scale Life Satisfaction Health behavior score}

$\begin{array}{lllllll}(1) & (2) \quad(3) \quad(4) \quad(5) \quad(6)\end{array}$

$\begin{array}{lllllll} & \text { 6-month } & \text { 12-month } & \text { 6-month } & \text { 12-month } & \text { 6-month } & \text { 12-month } \\ \text { Treated ward } & -0.283^{* *} & -0.038 & 0.491^{* *} & 1.024^{* * *} & -0.097^{* *} & -0.068^{* *} \\ & (0.135) & (0.166) & (0.188) & (0.290) & (0.045) & (0.046) \\ \text { Sample Size } & 6059 & 6059 & 6059 & 6059 & 6059 & 6059 \\ \text { Adjusted R-Squared } & 0.005 & 0.000 & 0.011 & 0.026 & 0.009 & 0.033 \\ \text { Adjusted P-value } & 0.036 & 0.820 & 0.018 & 0.001 & 0.017 & 0.022 \\ \text { Control Group Mean } & 9.133 & 8.583 & 6.658 & 6.000 & 0.278 & 0.228\end{array}$

Notes: Robust standard errors in parentheses, clustered at the ward level. P-values were corrected using the FWER Hochberg index. The unit of observation was all the beneficiaries. The Geriatric Depression Scale was constructed using a set of questions aimed at estimating the beneficiaries' depression level; higher scores were associated with greater depression. Life Satisfaction was the sum of yes/no questions related to the quality of life. Health behavior indicated the number of risky behaviors in which beneficiaries engaged. Standard errors in parentheses, clustered at the ward level.

***Significant at the $1 \%$ level.

**Significant at the $5 \%$ level.

*Significant at the $10 \%$ level. 
Table 4: Direct Outcomes: ITT Effects of the Ekiti State Pension Program (Vulnerability)

\section{Vulnerability index Food Security Financial Inclusion}

\begin{tabular}{|c|c|c|c|c|c|c|}
\hline (1) & (1)6-month & (2)12-month & (3)6-month & (4)12-month & (5)6-month & (6)12-month \\
\hline Treated ward & $\begin{array}{l}-0.161 \\
(0.094)\end{array}$ & $\begin{array}{l}-0.333^{* * *} \\
(0.119)\end{array}$ & $\begin{array}{l}-0.227 \\
(0.128)\end{array}$ & $\begin{array}{l}-0.404^{* * *} \\
(0.124)\end{array}$ & $\begin{array}{l}0.012 \\
(0.338)\end{array}$ & $\begin{array}{l}0.209 \\
(0.203)\end{array}$ \\
\hline Sample Size & 5984 & 5747 & 6059 & 6059 & 6059 & 6059 \\
\hline Adjusted R-Squared & 0.003 & 0.016 & 0.003 & 0.012 & 0.000 & 0.001 \\
\hline Adjusted P-value & 0.174 & 0.010 & 0.174 & 0.003 & 0.972 & 0.302 \\
\hline Control Mean & $\begin{array}{l}0.062 \\
(1.470)\end{array}$ & $\begin{array}{l}0.153 \\
(1.466)\end{array}$ & $\begin{array}{l}1.694 \\
(2.249)\end{array}$ & $\begin{array}{l}1.411 \\
(2.029)\end{array}$ & $\begin{array}{l}2.473 \\
(3.643)\end{array}$ & $\begin{array}{l}2.647 \\
(2.628)\end{array}$ \\
\hline
\end{tabular}

Notes: Robust standard errors in parentheses, clustered at the ward level. P-values were corrected using the FWER Hochberg index. The unit of observation was all beneficiaries. The "Vulnerability Index" was constructed using PCA methodology variables that describe crime, food shortages, migration, and child labor. "Food Security" is self-explanatory "Financial Inclusion" was constructed as the sum of indicator variables related to whether beneficiaries had a bank account, whether they borrowed money from the formal system, whether they had savings, and the type of financial institutions they had used in the previous month.

***Significant at the $1 \%$ level.

**Significant at the $5 \%$ level.

*Significant at the $10 \%$ level.

Table 5: Direct Outcomes: ITT Effects of the Ekiti State Pension Program (Labor Supply)

Work Labor supply Participation index

(1)
(2)
(3)
(4) (5)
(6)

$\begin{array}{lllllll}\text { Treated ward } & -0.003 & 0.033 & -0.410 & -1.493^{*} & 0.046 & 0.613^{*} \\ & (0.012) & (0.017) & (0.401) & (0.695) & (0.305) & (0.289) \\ \text { Number } & 6060 & 6060 & 6060 & 6060 & 6059 & 6059 \\ \text { Adjusted R-Squared } & 0.000 & 0.001 & 0.000 & 0.000 & 0.000 & 0.003\end{array}$




$\begin{array}{lllllll}\text { Adjusted P-value } & 0.994 & 0.504 & 0.666 & 0.075 & 0.998 & 0.075 \\ \text { Control Mean } & 0.674 & 0.684 & 12.151 & 7.171 & 21.159 & 20.892 \\ & (0.469) & (0.465) & (16.469) & (11.537) & (5.168) & (6.391)\end{array}$

Notes: Robust standard errors in parentheses, clustered at the ward level. P-values were corrected using the FWER Hochberg index. The unit of observation was all beneficiaries. "Work" is an indicator variable which is equal to 1 if the beneficiary is working and 0 otherwise. "Hours Worked per capita f" and "Total Hours Worked" refer to the number of hours per household member and per household, respectively.

*** Significant at the $1 \%$ level.

**Significant at the $5 \%$ level.

*Significant at the $10 \%$ level.

Table 6: Indirect Outcomes: ITT Effects of the Ekiti State Pension Program (Other Household Members)

\section{Work (1) Hours Worked per capita (2) Total Hours Worked (3)}

$\begin{array}{llll}\text { Treated ward } & 0.028 & -1.074^{* * *} & -6.411^{* *} \\ & (0.038) & (0.342) & (2.878) \\ \text { Sample size } & 23157 & 23157 & 23157 \\ \text { Adjusted R-Squared } & 0.001 & 0.001 & 0.003 \\ \text { Adjusted P-Value } & 0.509 & 0.008 & 0.433 \\ \text { Control Mean } & 0.492 & 32.253 & 65.13 \\ & (0.426) & (17.366) & (59.028)\end{array}$

Notes: Robust standard errors in parentheses, clustered at the ward level. The unit of observation was all those who lived in a household. Work is an indicator variable of whether the individual was working or not, "Hours worked per capita" is the total number of hours worked in a week, and "Total Hours Worked" indicates the total number of hours worked by all members of a household.

*** Significant at the $1 \%$ level.

**Significant at the $5 \%$ level.

*Significant at the $10 \%$ level. 


\section{Table 7: Indirect Outcomes: ITT Effects of the Ekiti State Pension Program (Household Level)}

\begin{tabular}{|c|c|c|c|c|c|}
\hline & (1) HH Size & (2) Asinh -Income & (3) Asinh -Expenditure & (4) Asinh -Healthcare & (5) Asinh -Saving \\
\hline Treated ward & $\begin{array}{l}-0.454^{* * *} \\
(0.067)\end{array}$ & $\begin{array}{l}0.069 * * \\
(0.028)\end{array}$ & $\begin{array}{l}-0.064^{* * *} \\
(0.020)\end{array}$ & $\begin{array}{l}-0.298^{* * *} \\
(0.109)\end{array}$ & $\begin{array}{l}2.135^{* * *} \\
(0.396)\end{array}$ \\
\hline Sample Size & 6132 & 6132 & 6132 & 6132 & 6132 \\
\hline Adjusted R-Squared & 0.009 & 0.002 & 0.002 & 0.002 & 0.012 \\
\hline Adjusted P-Value & 0.000 & 0.015 & 0.005 & 0.013 & 0.000 \\
\hline Control Mean & $\begin{array}{l}4.970 \\
(2.452)\end{array}$ & $\begin{array}{l}9.765 \\
(1.232)\end{array}$ & $\begin{array}{l}9.954 \\
(1.246)\end{array}$ & $\begin{array}{l}6.622 \\
(3.139)\end{array}$ & $\begin{array}{l}-3.099 \\
(9.590)\end{array}$ \\
\hline
\end{tabular}

Notes: Robust standard errors in parentheses, clustered at the ward level. The unit of observation was all those who lived in a household. The outcome variables displayed in Columns 2 through 6 are the inverse hyperbolic sine of the total monthly income, spending, and savings of the households.

*** Significant at the $1 \%$ level.

$* *$ Significant at the $5 \%$ level.

*Significant at the $10 \%$ level.

\section{A. Outcome Variables}

Most of the outcome variables were composites constructed from the response options provided in survey questionnaires.

\section{A.1 Direct Outcomes}

\section{Mental Health}

We first consider the Geriatric Depression Scale (GDS), which quantifies depression symptoms and lack of self-esteem. This scale is based on the elderly respondent's answer to fifteen yes/no questions related to how they feel about life (whether they feel like valuable people or whether they have energy to undertake daily activities, for example). The responses were then added to give a total score for the individual. Higher scores indicated a higher probability of problems in mental health. This scale was first developed by Sheikh and Yesavage (1986) and later used by Galiani et al. (2016) and Bando et al. (2016). 


\section{The following questions were asked in the first and second follow-up surveys in order to construct the GDS:}

1. In general, do you feel satisfied with your life?

2. Have you given up many activities or personal interests?

3. Do you feel something is missing from your life?

4. Are you often bored?

5. Are you cheerful and in good spirits most of the time?

6. Are you afraid that something bad will happen?

7. Do you feel happy/pleased most of the time?

8. Do you feel helpless or ignored often?

9. Would you rather stay at home than go out and do new things?

10. Do you think you have more memory-related problems than most people?

11. Do you think it's wonderful to be alive?

12. Do you think your life is worthless or unimportant?

13. Are you a valuable person?

14. Do you have enough energy for everyday life?

15. Do you have enough money to cover your needs?

Similarly, we constructed a six-question measure of Life Satisfaction using the same methodology to sample whether subjects were satisfied with aspects of their lives: general health, themselves, the ability to perform everyday activities, personal relationships, the conditions of their homes, and relationships with family members. A higher score was associated with a higher level of satisfaction with life.

\section{The list of questions is presented below:}

1. How happy are you with your health?

2. How happy are you with yourself?

3. How happy are you with your ability to perform everyday life activities?

4. How happy are you with your personal relationships?

5. How happy are you with your physical living conditions?

6. How happy are you with the relationships you have with your children / grandchildren?

7. Considering all of the mentioned aspects, in general, how happy are you with your life today?

8. Do your opinions count when making decisions about household spending?

9. Do you think your relationship with your family is Excellent - Good - Fair - Poor - Very Bad?

Thirdly, the Health Behavior Score approximated the number and types of risky behaviors in which beneficiaries engaged. In particular, we focused on alcohol consumption and cigarette or other tobacco use. The variable was constructed as the sum of responses as follows: (i) between one and five points according to consumption of cigarettes, tobacco, or alcoholic beverages; and (ii) one, two, or three points for weekly spending on tobacco or alcohol. Higher values were associated with riskier behavior.

\section{Vulnerability}

We measured beneficiaries' exposure to risk, including their general vulnerability, their food insecurity, and their level of financial inclusion. Specifically, we constructed an index to asses vulnerability using PCA methodology with variables that indicated whether a member of the household engaged in child labor, whether there were food shortages in the household, whether any member had been the victim of crime, and migration shocks. The "Food Security" measure was constructed using questions regarding food intake over the previous six months. "Financial Inclusion" was constructed as the sum of such indicator variables as whether beneficiaries had a bank account, whether they borrowed money from the formal system, whether they had savings, and the types of institutions (formal banking as well as informal systems) in which they conducted transactions in the previous month. 


\section{Labor Supply}

We considered three beneficiary labor-supply outcomes. The first was an indicator of whether the beneficiary had worked in the last six months, or share of beneficiaries working for pay. The second variable was the reported number of hours worked in the previous week.

Next, we considered community participation with a variable called "Participation Index," constructed as the sum of seven questions that assessed the level of integration of individuals within their communities. The set of questions included (i) whether beneficiaries felt included in their communities; (ii) whether the elderly individual participated in community activities; (iii) whether the community contributed to the well-being of the elderly individual; (iv) whether there was peer networking; ( $v$ ) whether the Ekiti government provided care for the elderly individual; (vi) whether the scheme would continue; and (vii) whether the senior citizen was happy. Responses ranged from zero for strong disagreement to four for strong agreement.

\section{A.2 Indirect Outcomes}

\section{Labor Supply}

We analyzed the labor supply of other household members by looking at three variables: their employment status, the number of hours worked individually, and the total hours worked per household. Employment Status was an indicator variable of whether household members had worked during the month prior to the interview. The "number of hours worked" was the average number of hours worked per week in the previous month. Finally, "total hours worked" was the arithmetic sum of the average reported hours worked by all the household members.

\section{Household Level}

The final set of outcomes analyzed changes in household size (the number of individuals living in a household, including the beneficiary) and income and spending patterns. Income was measured by summing self-reported income of all household members in the month prior to the interview. Next, total household spending included healthcare, food, non-food, and other spending. We present specific healthcare costs in Column 4 of Table 7. These include: (i) the cost of services used by household members, (ii) the cost of medicines, (iii) the cost of transportation to the healthcare provider, and (iv) hospitalization costs, if any. The last column in Table 4 includes self-reported savings.

Finally, to handle extreme values of the income and expenditure variables, we calculated the Hyperbolic Sine transformation. In particular, this transformation allowed us to keep zero values defined as log $(y i+(y 2+1) 2)$. Thus, it can be interpreted in the same way as a standard logarithmic dependent variable for greater numbers while also being defined for zero values.

\section{B Appendix Tables}

Table B.1: Descriptive Characteristics: Individuals in All Periods

\section{Panel A: Demographics \\ Treatment Control \\ Mean SD Mean SD}

Diff. P-value

Age 78.14912 .70178 .46712 .6580 .331

Male 0.3120 .7970 .3080 .7940 .827

Household size 3.1076 .1012 .9216 .0590 .235

Monogamous 0.3811 .3170 .3891 .3100 .820 
Polygamous 0.1410 .7140 .1080 .7110 .080

Widowed 0.4261 .3790 .4681 .3710 .248

Literacy 0.1220 .6280 .09740 .6250 .127

Attended School 0.1741 .0040 .1210 .9990 .044

\section{Panel B: Labor}

Employed 0.2681 .5310 .2431 .5220 .520

Subsistence farmer 0.2081 .3660 .1911 .3580 .637

Non subsistence farmer 0.0070 .1610 .0120 .1600 .226

Other-non farming job 0.0530 .4830 .0390 .4810 .268

\section{Panel C: Support}

Receives Support 0.4021 .3220 .4571 .3150 .109

Support Child 0.1111 .0100 .1401 .0040 .255

Support Relative 0.0681 .0420 .0981 .0360 .252

Amount 941.68 3547.991085.313529.66 0.117

\section{Panel D: Health Behavior}

Smoke 0.0500 .6760 .0260 .6710 .166

Alcohol Consumption 0.117 1.036 0.110 1.029 0.792

Health Self-Assessment 2.761 3.500 2.687 3.469 0.417

Confidence in ability 2.5276 .1042 .5756 .0480 .759

Inclusion level 2.314 4.544 2.216 4.4910 .405

N 29883069

Joint P-Value 0.356

Notes: Household size indicates the number of people living in the same household as the beneficiary. "Literacy" and "attended school" are self-explanatory. All variables in panels B, $C$, and D are were reported for the month prior to the interview. "Hours Worked" is the average number of hours worked per day during the previous month. "Amount" is the amount of NGN received in a month by the beneficiary. All variables in Panel D were self-reported.

***Significant at the $1 \%$ level.

**significant at the $5 \%$ level.

*Significant at the $10 \%$ level. 
Table B.2: Direct Outcomes ITT Effects of the Ekiti State Pension Program Mental Health with controls

Geriatric Depression Scale Life Satisfaction

\section{Treated ward}

Number

Adjusted R-Squared

Control Group Mean

Control Group SD

Adjusted P-Value

\section{Controls}

\section{LGA Fixed Effects}

1) 6-month

$-0.285^{* *}$

(0.134)

6060

0.008

9.133

$(2.043)$

0.036

Yes

Yes
Health behavior score

\section{(2) 12-month \\ (3) 6-month}

$-0.174$

(0.193)

5747

0.002

8.583

(2.846)

0.378

Yes

Yes
$0.494^{* * *}$

(0.186)

6059

0.020

6.658

(2.304)

0.017

Yes
(4) 12-month

$0.915^{* * *}$

(0.281)

5746

0.027

6

(3.216)

0.003

Yes

Yes

$\begin{array}{ll}\text { (5) 6-month } & \text { (6) 12-month } \\ -0.162^{* * *} & -0.177^{* * *} \\ (0.045) & (0.047) \\ 6060 & 5604 \\ 0.009 & 0.011 \\ 1.404 & 1.424 \\ (0.955) & (0.956) \\ 0.017 & 0.017 \\ \text { Yes } & \text { Yes } \\ \text { Yes } & \text { Yes }\end{array}$

(5) 6-month

$-0.162^{* * *}$

Notes: Robust standard errors in parentheses, clustered at the ward level. P-values were corrected using the FWER Hochberg index. The unit of observation was all beneficiaries. The Geriatric Depression Scale was constructed using a set of questions that estimated beneficiaries" depression level; higher scores were associated with greater depression. Life satisfaction is was the sum of yes/no questions related to quality of life. Health behavior indicates the number of risky behaviors in which beneficiaries engaged. Standard errors in parentheses, clustered at the ward level.

***Significant at the $1 \%$ level.

**Significant at the $5 \%$ level.

*Significant at the $10 \%$ level. 


\section{Table B.3: Direct Outcomes: ITT Effects of the Ekiti State Pension Program (Vulnerability with Controls)}

\section{Food Security Financial Inclusion}

\begin{tabular}{|c|c|c|c|c|c|c|}
\hline & (1) 6-month & (2) 12-month & (3) 6-month & (4) 12-month & (5) 6-month & (6) 12-month \\
\hline Treated ward & $\begin{array}{c}-0.156^{*} \\
(0.093)\end{array}$ & $\begin{array}{l}-0.329 * * * \\
(0.117)\end{array}$ & $\begin{array}{l}-0.222 * \\
(0.127)\end{array}$ & $\begin{array}{l}-0.432^{* * *} \\
(0.129)\end{array}$ & $\begin{array}{l}0.021 \\
(0.338)\end{array}$ & $\begin{array}{l}0.181 \\
(0.222)\end{array}$ \\
\hline Number & 5984 & 5747 & 6060 & 5747 & 6060 & 5747 \\
\hline Adjusted R-Squared & 0.003 & 0.019 & 0.003 & 0.013 & 0.002 & 0.002 \\
\hline Control Group Mean & 0.062 & 0.153 & 1.694 & 1.411 & 2.473 & 2.647 \\
\hline Control Group SD & $(1.472)$ & $(1.466)$ & (2.249) & (2.029) & (3.643) & $(2.628)$ \\
\hline Adjusted P-Value & 0.186 & 0.010 & 0.186 & 0.002 & 0.962 & 0.420 \\
\hline Controls & Yes & Yes & Yes & Yes & Yes & Yes \\
\hline LGA Fixed Effects & Yes & Yes & Yes & Yes & Yes & Yes \\
\hline
\end{tabular}

Robust standard errors in parentheses, clustered at the ward level. P-values were corrected using the FWER Hochberg index. The unit of observation was all beneficiaries. The "Vulnerability Index" was constructed using PCA methodology variables that described crime, food shortages, migration, and child labor. "Food Security" is self-explanatory. Finally, "Financial Inclusion" was constructed as the sum of indicator variables of whether the beneficiaries had a bank account, had borrowed money from the formal system, had savings, and the type of institutions they had used in the previous month. Control variables included age, gender, and literacy of the beneficiaries.

***Significant at the $1 \%$ level.

**Significant at the $5 \%$ level.

*Significant at the $10 \%$ level. 
Table B.4: Direct Outcomes: ITT Effects of the Ekiti State Pension Program (Labor Supply with Controls)

Work Labor supply Participation index
(1)
(2)
(3)
(4)
(5)
(6)

Treated ward

6-month
-0.009

12-month

6-month
-0.393

12-month 6-month

12-month

$(0.011)$

(0.015)

(0.352)

$-1.258^{*}$

0.035

0.243

Number

6060

5747

6060

(0.693)

(0.303)

(0.310)

Adjusted R-Squared

0.225

0.217

0.121

5467

6059

5746

Control Group Mean

0.684

12.151

0.053

0.012

0.004

0.674

(16.469)

7.309

21.159

20.892

Control Group SD

(0.469)

(0.465)

0.916

0.908

Controls

Yes

0.225

Yes

Yes

Yes

(11.604)

(5.168)

(6.391)

LGA Fixed Effects

Yes

Yes

0.225

0.916

0.418

Yes

Yes

Yes

Yes Yes Yes

Notes: Robust standard errors in parentheses, clustered at the ward level. P-values were corrected using the FWER Hochberg index. The unit of observation was all beneficiaries. "Work" was an indicator variable equal to 1 if the beneficiary was working and 0 otherwise. "Hours Worked per capita" and "Total Hours Worked" refer to the number of hours per household member and per household respectively. Control variables included the age, gender, and literacy of beneficiaries.

***Significant at the $1 \%$ level.

**significant at the $5 \%$ level.

*Significant at the $10 \%$ level. 
Table B.5: Indirect Outcomes: ITT Effects of the Ekiti State Pension Program (with Controls, Other Household Members)

\begin{tabular}{|c|c|c|c|}
\hline & Work (1) & $\begin{array}{l}\text { Hours Worked per } \\
\text { capita (2) }\end{array}$ & Total Hours Worked (3) \\
\hline Treated ward & $\begin{array}{l}0.023 \\
(0.038)\end{array}$ & $\begin{array}{l}-1.145^{* * *} \\
(0.347)\end{array}$ & $\begin{array}{l}-6.542^{* *} \\
(2.871)\end{array}$ \\
\hline Sample size & 23157 & 23157 & 23157 \\
\hline Adjusted R-Squared & 0.001 & 0.001 & 0.003 \\
\hline Adjusted P-Value & 0.509 & 0.008 & 0.433 \\
\hline Control Mean & $\begin{array}{l}0.492 \\
(0.426)\end{array}$ & $\begin{array}{l}32.253 \\
(17.366)\end{array}$ & $\begin{array}{l}65.13 \\
(59.028)\end{array}$ \\
\hline \multicolumn{4}{|c|}{$\begin{array}{l}\text { Notes: Robust standard errors in parentheses, clustered at the ward level. The unit of } \\
\text { observation was all the household members who live in the households. Work is an indicator } \\
\text { variable of whether the individual was working or not, "hours worked per capita" is the total } \\
\text { number of hours worked in a week, and "total hours worked" indicates the total number of } \\
\text { hours worked in a household. } \\
\text { ***Significant at the } 1 \% \text { level. } \\
\text { **Significant at the } 5 \% \text { level. } \\
\text { *Significant at the } 10 \% \text { level. }\end{array}$} \\
\hline
\end{tabular}


Table B.6: Indirect Outcomes: ITT Effects of the Ekiti State Pension Program (Household Level)

\begin{tabular}{|c|c|c|c|c|c|}
\hline & (1) HH Size & (2) Asinh-Income & (3) Asinh-Expenditure & (4) Asinh-Healthcare & (5) AsinhSaving \\
\hline Treated ward & $\begin{array}{l}-0.426^{* * *} \\
(0.066)\end{array}$ & $\begin{array}{l}0.034 \\
(0.025)\end{array}$ & $\begin{array}{l}-0.045^{* *} \\
(0.022)\end{array}$ & $\begin{array}{l}-0.261^{* * *} \\
(0.098)\end{array}$ & $\begin{array}{l}1.208^{* * *} \\
(0.291)\end{array}$ \\
\hline Sample Size & 6132 & 6132 & 6132 & 6132 & 6132 \\
\hline Adjusted R-Squared & 0.009 & 0.002 & 0.002 & 0.002 & 0.012 \\
\hline Adjusted P-Value & 0.000 & 0.015 & 0.005 & 0.013 & 0.000 \\
\hline Control Mean & $\begin{array}{l}4.970 \\
(2.452)\end{array}$ & $\begin{array}{l}9.765 \\
(1.232)\end{array}$ & $\begin{array}{l}9.954 \\
(1.246)\end{array}$ & $\begin{array}{l}6.622 \\
(3.139)\end{array}$ & $\begin{array}{l}-3.099 \\
(9.590)\end{array}$ \\
\hline
\end{tabular}

Notes: Robust standard errors in parentheses, clustered at the ward level. The unit of observation is all the household members who live in the households. The outcome variables displayed in Columns 2 through 6 are the inverse hyperbolic sine of total monthly income, spending, and savings of the households.

$* * *$ Significant at the $1 \%$ level.

**Significant at the $5 \%$ level.

*Significant at the $10 \%$ level. 